\title{
Wokół druku ulotnego Epitaphium... z czasów rewolucji francuskiej
}

Aurelia Has 


\section{Aurelia Has}

\section{Wokół druku ulotnego Epitaphium... z czasów rewolucji francuskiej} wydania może budzić zainteresowanie z kilku powodów. Po pierwsze: wśród utworów poetyckich inspirowanych wydarzeniani rewolucji francuskiej, rozpowszechnianych głównie w rękopisach, znalazł się w grupie nielicznych wierszy, które przeszły przez druk. Po drugie: nie był dotychczas wykorzystywany przez badaczy', chociaż przynosi materiał mogący zaciekawić szerokiego czytelnika, a nade wszystko badaczy literatury i historyków sensu stricto. Jest dokumentem pozwalającym zbliżyć nas do prawdy historycznej i stanowi świadectwo naszej kultury literackiej. Po trzecie: druczek jest zagadkowy pod względem kompozycji. Został błędnie zinwentaryzowany pod tytułem Epitaphimm Regis Galliae Ludovici XIT (Biblioteka Instytutu Badań Literackich Polskiej Akademii Nauk w Warszawie, sygn. XVIII.2.239), gdy tymczasem — jak wskazuje choćby porównanie z egzemplarzem w bibliotece Uniwersytetu Warszawskiego (sygn. 28.20.4.1598/2, k. nlb 4) — są to dwa osobne wolanty. Pogląd ten znajduje potwierdzenie w bibliografii Estreichera (t. 21, s. 6, co prawda bez precyzyjnego określenia roku wydania, ale z zaznaczeniem, że odnosi się do lat dziewięćdziesiątych XVIII stulecia) oraz w Nou'y'n Korbucie (t. 6, cz. 1, s. 625, z ogólnikowo sformulowaną datacją: „z czasów rewolucji francuskiej”). Te cnigmatyczne informacje dotyczące czasu powstania Epitaphium można uśścślić. Druk powstał po 10 maja 1794 roku, na co

1 Fragmenty utworów wykorzystuje Krystyna Maksimowicz w: eadem, Reu'olucja francusk'a "w poczji polit)'znej czasu konfederacji targourickiej, w: W' strong Francji... Z problemón literatur' i kultury polskiegu Ośl'icecnia, red. E. Z. Wichrowska, Warszawa 2007, s. 33-50. 
wskazuje nagrobek Elżbiety, siostry Ludwika XVI, straconej w tym dniu. Inne utwory zawierające realia odnoszą się do okresu wcześniejszego.

Wolant Epitaphinm Regis Galliae Ludovici XVI zawiera dwa wiersze nagrobkowe poświęcone Ludwikowi XVI, jeden odwołıjący się do Marii Antoniny oraz dystych adresowany do Francji w dwóch wersjach.

Na nazwisko autora druku Epitaphium wskazują podane na nim inicjaly „A. Ł.”. Kryptonim ten nie sprawia co prawda większego kłopotu, jako że w ten sposób podpisywał swoje utwory eksjezuita Adam Łabęcki, ponieważ jedıak druk zawiera epigramaty pisane po łacinie i ich przekłady na język polski, nasuwa się pytanie, czy zarówno oryginał, jak i tłumaczenie były dziełem tego samego autora. W rozwiązaniu tej kwestii odwołujemy się do praktyki stosowanej powszechnie przez Łabęckiego, który swoje utwory wydawał w dwı językach (lacińskim i polskim), co ıpoważnia do stwierdzenia, że obie wersje językowe wyszły spod jego pióra. W ten sposób wydał na przykład epigramaty związane z odsłonięciem pomnika Jana III Sobieskiego w Łazienkach (Epigramma in statuam Sobiescianam) czy wiersze poświęcone Tadeuszowi Kościuszce (Thaddaeus Kościnszko de se ipso, b. m. [1794]).

Urodzony w 1730 roku poeta był świadkiem wielı ważnych wydarzeń publicznych i prywatnych w kraju. Wobec rewolucji nad Sekwaną, która wywołała silny oddźwięk w Europie, w tym w Polsce, nie mógł pozostać obojętny. Z ducha rewolty francuskiej wyrasta jego praca Praesens pernersitas mundi w języku łacińskim i w przekładzie na język polski (pod tytułem Teraźniejsza przcu'rotność śuiata), podejmująca tematykę trudnej sytuacji Kościoła, by nie rzec: prześladowania, w rewolucyjnej Francji. Chociaż wiemy, że tematyka związana z rewolucją francuską jest obecna w twórczości Łabęckiego, to brakuje nam informacji, czy sam autor był w jakimś okresie swego życia w tym kraju.

Na druk Epitaphium składa się 21 utworów epigramatycznych, z których dziesięć poświęconych jest ofiarom rewolucji francuskiej, cztery wyrastają z atmosfery fermentu rewolucyjnego, dwa odnoszą się do największych filozofów oświecenia francuskiego, a pięć trudno byłoby powiązać z jakimikolwiek realiami, na co wskazują już choćby tytuły: Nagrobek męża cnotlin'ego; Panna pięknie ubrana, ale uboga; Peu'ny w'ygnaniec z ojcz)'zuy; Mitośc; Choroba francuska.

Zasadniczy trzon wolantu stanowią nagrobki o wyraźnym adresie personalnym. Są to członkowie najbliższej rodziny króla francuskiego: Maria Antonina, wspomniana wcześniej Elżbieta i Filip Égalité. Im też poświęcono najwięcej utworów: królowej - trzy, a siostrze i kuzynowi królewskiemu po dwa.

Pozostali bohaterowie teatru rewolucji uwiecznieni zostali w większości w pojedynczych wierszach. Są to: biskup Claude Fauchet, dowódca wojskowy Adam-Philippe Custine, sławny Jean-Paul Marat, jego przyjaciel, później oponent Jacques-Piérre Brissot, mówca Antoine-Pierre-Joseph Barnave, mer Paryża Jean-Sylvain Bailly oraz Pierre-Louis Manuel. 
Na osobną uwagę zasługują dwa epigramaty odnoszące się do Woltera i Rousseau. Można przypuszczać, że w ten sposób poeta akcentował wpływ myśli filozoficznej tych intelektualistów na genezę, a potem bieg wydarzeń w rewolucyjnej Francji. Co więcej, Rousseau był powszechnie czytany i przywoływany przed rewolucją i w jej czasie jako jej patron i duchowy przywódca. To jego Umou'a spoteczna, w większym, czy mniejszym stopniu, legła u podstaw reform proponowanych przez rewolucjonistów. Propagowana przez filozofa we wspomnianym dziele teoria głosząca zasadę równości i wolności człowieka miała niemały wpływ na kształtowanic się ideologii rewolucyjnej we Francji.

Kolejnego myśliciela - Woltera — autor nie oszczędzil głównie za jego nienawistny stosunek do religii. Wolter stał się symbolem wieku, w którym przyszło mu zyć, a jego światopogląd nie pozostał bez istotnego wpływu na wydarzenia we Francji pod koniec XVIII wicku².

Pozostałe utwory w większości utrzymane są w formie odezwy zmarłych do społeczeństwa, z myślą o przestrodze i z nadzieją na wywolanie refleksji związanej z terrorem rewolucyjnym. Są one dość schematyczne, tyle że zamiast pochwały zmarłego, jak to zwykle w nagrobkach bywa, ujawniają negatywne emocje piszącego. Pojawia się w nich kilka głównych motywów:

— zmienności losu ludzkiego,

- przegranego życia,

- równości wobec śnierci,

- ekspiacji.

Pierwszy motyw dominuje w nagrobkach poświęconych Marii Antoninie (straconej 16 października 1793) i Pierre-Louis Manuelowi (zm. 14 listopada 1793). Królowa żali się na swój upadek i przestrzega czytelnika przed zmiennością losu:

Hic decimi Lodoici sexti decubat axor;

Unde loqui nobis verba videtur ea:

„Aspice quisque meam vitam! Simml aspice mortem!

Quam mea sors humilis, quae fuit alta prius,

Aspice! sitque tibi regum crux nostra magistra,

Est nobis quae hodie, cras tibi forsan erit".

\footnotetext{
2 Nagrobek Woltera drukowany w: A. Siomkajto, Mała muza: od Reja do Leca: antologia epigramatyki polskiej, Warszawa 1986, s. 234, za: A. Łabęcki, Wiersze krótkie, częściq nou'o utożone, częścią z różuych u'ierszopisón' zebrane i na polskic przetożone, na cztery ksigżki podzielone. [Warszawa] 1786. Świadczy to o tym. że autor lub wydawca włączył nagrobek Woltera do zbioru Epitaphinm...
} 
Tu żona Szesnastego Ludwika spoczywa,

Skądże do nas, zda się, w te słowa się odzywa:

„Patrz każdy na me życia i śmierci uciski,

Jak los mój spadł z wysoka na stan bardzo niski,

Patrz, a ucz się z nas królów, jaki krzyż dźwigamy,

Ten ty jutro mieć możesz, który my dziś mamy".

Podobną wymowę ma epigramat Emmanuela:

Vertitur ut rota prosperitas (res panditur ipsa),

Quaque via aes currit, pone recurrit ea.

Nuper ego quid eram? Patefit: vir magnus herorum

Nunc quali vilis homo perdor ab ense gravi.

Ut lupus humano fervebam sanguine pasci,

Et modo iam pascor lurco crnore meo.

Tak to jest: w czyj dom kołem, rzecz sama oznacza,

Szczęście się toczy, z niego kołem się wytacza.

Czym ja bylem, wie każdy: mąż wielki przed pany,

Dziś ginę jak chłop prosty, od miecza, związany.

Jak wilk, żarłok na ludzką byłem krew i życie,

Dziś oto żrę krew wlasną, aż nadto obficie.

Wśród ofiar rewolucji widzimy też Jean-Paul Marata (zabitego 13 lipca 1793), którego nie dosięgła hańba gilotyny, ale ostrze noża rzeźnickiego w ręku kobiety, wymierzone w imię uwolnienia ziemi od Antychrysta. Młoda, religijna Normandka, Charlotte Corday, przybyła do Paryża i odnalazła „Pragnącego krwi potwora”, odpowiedzialnego za masakry wrześniowe z 1792 roku. Prawdopodobnie, zadając mu śmierć, uchroniła go przed niechybną gilotyna, pod którą w rezultacie tego czynu sama poniosła śmierć̉. W usta Marata poeta włożył słowa:

Hic Marat orator recubo qui gentis amator

Vel potius tulgi praceo dolosus cram.

Edocui populum, libertas quam decet illum,

Et mihi prompta nocens decedus ipsa tulit.

Cum corpus puris undis a forde lavarem,

Cor fixit cultro prava virago metum.

Profuit ecce milii libertas! Multa loquebar

De qua tutus ubi, munc cubo mutus ibi.

${ }^{3}$ Zob. S. Loomis, Paris in the Terror. Jume 1793 - July' 1794, London 1964; P. Gaxotte, Ren'olucja francuska, tł. J. Furuhielm, popr. i uzup. A. Zawilski, E. Kuczkowska, Gdańsk 2001. 
Tu Marat leżę, mówca, czy przyjaciel dawny

Ludu, czy-li zwodziciel dla pospólstwa jawny.

Nauıczałem, jak wolność jest ludzką ozdobą,

Aż tego sam z niesławą przyplacilem sobą.

Gdym używal kąpieli, by mię oczyścila,

Zla niewiasta wskroś nożem serce me przebiła.

Otóż mam zysk z wolności! Gdzie się rozprawiało

Wiele o niej, tam leży me zamilkłe ciało.

Podobną myśl znajdujemy w nagrobku Custine’a (zm. 28 sierpnia 1793). On bowiem również wspomina swoje życie, które nie przyniosło mu oczekiwanej sławy, ale śmierć. I to nie śmierć chwalebną na polı bitwy, lecz haniebną, niegodną dowódcy, wielkiego generała, zdobywcy Moguncji. Poeta wystawił mu następujący nagrobek:

Millenos fortis vincebam belliger hostes,

Vix mihi par heros, victor et alter erat.

Mors mihi laeta foret, morcerer si caesus ab hoste,

Proh dolor! a propriis civibus ense necor:

Pro meritis ergo meriu quac dona referre?

Invictus victor procido vinctus homo.

Tysiączny-m na potyczkach zwycięstwa wygrywał.

Ledwie mi który rycerz lub wódz wyrównywał,

Gdybym ginął na wojnie, umierałbym śmiało,

Niż gdy z woli mych ziomków kat me dręczy ciało.

Cóż mam za korzyść z usług, wódz nieprzekonany?

Ginę oto jak wieśniak, okuty w kajdany.

A ileż ironii znajdujemy w śmierci Brissota (31 paździennika 1793), który bronił praw procesowych skazańców i wypowiadał się zdecydowanie przeciwko karze śmierci oraz wszelkiej formie okaleczania ${ }^{+}$, a który odzywa się zza grobu w te słowa:

Nunc pereo misere tota contemptus in ora

Ut fir suspensus, latro vel, ense secor.

Dziś ginę, w calym kraju od wszystkich wzgardzony,

Niby zbójca czy złodzicj w polı powieszony.

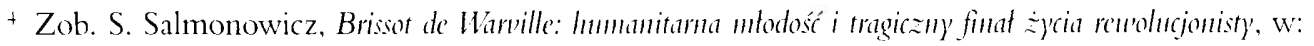
idem, Sylu'ctki spod giloty'n', Warszawa 1989, s. 61-87. 
Z kolei nagrobek biskupa Faucheta (zm. 31 października 1793) oddaje karierę duchowną bohatera, którą zawdzięczał nie powołaniu, ale okolicznościom politycznym. Ten dostojnik kościelny miał przyczynić się do umniejszania znaczenia Kościoła i wprowadzania nowego, świeckiego, republikańskiego sposobu życia. Otrzymał sakrę biskupią z ranienia Rewolucji, nie bacząc na ekskomunikę papieską̧, o czym mowa w epigramacie:

Quis iacet hic? Antistes ego iaceo, cui Christi

Caelitus haud fuerat credita cura gregis.

Ipse sed intrusus fueram, et res temporis huins

Curavi potius quam vigilare gregem.

Desuper idcirco mulctor; caput ascia tetra,

Sen guilotina seidit pontificale meum.

Discite, pontifices, quivis vel disce sacredos,

Quid patiere lites si sine voce Dei!

Kto tu leży? Ja biskup, któremu oddana

Z woli Boskiej nie była kiedyś trzoda Pana.

Sam-em się wdarł w ten urząd, i bardziej szukałem

Ziemskich rzeczy, a trzody Pańskiej zaniedbalem.

Przeto ginę; biskupią niosę pod miecz głowę,

Czy gilotyna tnie życia mego osnowę?

Macie przykład, biskupi! masz, każdy kapłanie,

Co cię czeka, ktoś nie jest z woli Boskiej w stanie!

Motyw ekspiacji pojawia się w epigramacie odnoszącym się do przewodniczącego Zgromadzenia Narodowego i mera Paryża Jean-Sylvain Bailly’go (zm. 12 listopada 1793), odpowiedzialnego za masakrę na Polach Marsowych 17 lipca 1791 roku':

Praeses eram caetus libertatisque magister

Ore discrtus item, nempe Baillus ego,

Sed quia perverse vixi pietatis et hostis,

Quin etiam fidei perditor omnis eram,

Praeterea blasphemavi, nomenque nefandis

Laedere conabar fancibus ipse Dei,

Non tulit infanem blasphemum me De'us ultra,

Blasphemus iusto caesus ab chse mi.

'Zob. G. Lenôtre, Citoyen-Pontife, w: idem, La petite histoire. Sous le bonnet rouge, Paris 1936, s.14-20.

"Zob. La vie de Sy/huin Bailly', w: J.-S. Bailly, Ocunres posthumes... précédé de la vié littéraire et politique de cet homme illustre, Paris 1810. s. IX-LIV. 
Hic tandem decumbo miser, magis atque tremenda

Plus reus exspecto iura futura Dei.

Byłem rządcą sejmowym, krasomówca sławny,

Ja Bailly, wolności nauczyciel jawny.

Lecz że żyłem przewrotnie, bez cnót i bez wiary,

Owszem, biłem na wiarę żwawo i bez miary,

Nadtom bluźnił i takie z ust słowa miotałem,

Którymi lzyć samego Boga nie przestałem.

Nie chiciał Bóg dłużej cierpieć mej duszy szaleństwa,

Zdal bluźniercę pod kata topór okrucieństwa.

Tu więc leżą me nędzne i niezbożne zwłoki,

Czekając z nieba dalej na sroższe wyroki.

W podobnym duchu wspomina swoje niegodne życie i zasłużoną karę kuzyn królewski - ksiązę Orleanu Ludwik Filip Il, który przyjął imię Égalité (zm. 6 listopada 1793). W epigramacie wypomniano mu królobójstwo (głosowal za karą śmierci dla Ludwika XVI) i dążenie do objęcia tronu:

Vir Capet hic lateo, muper qui regis amicus

Frater, et cins eram post inimicus atrox.

Rex fieri volui sceptrumque prehendere regi,

Nunc fero pro sceptro, probra, sepulchra, necem.

Tu ja leżę, mąż Kapet, brat niegdyś życzliwy

Króla, a potem zdrajca i krwi jego chciwy.

Być królem i wziąć berlo królowi żądałem,

Zamiast berła obelgi, śmierć i grób dostalem.

Autor nie omieszkał ująć w puencie przysłowia o korzeniach biblijnych, w formie przestrogi, dla którego ilıstracją była historia Filipa Égalité:

Percipe, qui graderis, quam competat id milhi dictum:

Is cadit in foveam qui fodit alteri eam.

Zważ, kto idziesz, jak owo mi przystoi zdanie:

Że kto pod kim dół kopie, w ten się sam dostanie.

Ostatni bohaterowie, ofiary terroru, to sławny mówca Barnave (zm. 28 listopada 1793) i siostra Ludwika, Elżbieta. Ich nagrobki pełne są żalu i rozpamiętywania zgasłego życia.

Wśród utworów nagrobkowych nie mogło zabraknąć wiersza poświęconego gilotynie, która „tyle nicwinnych ludzi pogubiła”. Również ona uległa oskarżeniu, a jej przewinienie autor dostrzegł nade wszystko w tym, że, jak głosi puenta: 
[...] w tym najwięcej jednak przewiniełaś, Że tego, kto cię stworzył, najpierwej nie ścięlaś.

Szczególnie mocne słowa, aż dramatyczne w swojej ekspresji, zawarł autor w epigramacie Do Zgromadzenia Paryskiego:

Quis furor et quac te caepit dementia, caetus,

Qued quasi saeva lues perdere cuncta paras!

Contemmis sanctis remuisque fidem pietatis

Omnis et hostis! Adhuc pessima quaeque patras!

Ah, tandem resipise, genus! Mala cuncta repelle!

Sancta refer sanctis et profitere fidem!

Sin secundo, Deus, excelsis iace fulmen ab astis

Et gemus hoc rabidum tunde! Nefasque tere!

Tunde genus! Melius, quod natio corruet una,

Quam ruat omnis ea peste flagrante plaga.

Co za dzicz, i złość ciebie, Zgromadzenie, wzięła,

Że psujesz jak zaraza i najlepsze dziela?

Świętymi w niebie gardzisz, wiarę, cnoty gubisz,

Co jest gorszego, czynisz, i z tego się chlubisz!

Ej! przecież przydź ku sobie, nie grzesz już, narodzie!

Czcij świętych, wyznaj wiarę, pokutuj po szkodzie!

Inaczej: piorun z niebios rzuć, o Boże możny!

Zetrzyj tę dzikość wściekłą, zgub ten ród niezbożny!

Zgub ród ten; lepiej, jeden że zginie kraj caly,

Niz by świat wszystek przepadł od takiej zakały.

Ostatni z przywołanych utworów związanych z rewolucją odnosi się do drzewa wolności:

Indyta libertas! Arbor, non est cui radix:

Pileus est, sed ei, cerno, deesse caput.

\section{Vel}

Arbor libertatis acerba corruit aethra;

Censev: libertas quod ruet ipsa breni.

Zacna wolność! słup z drzewa bez korzenia nowy:

Ma czapkę, lecz pod czapką nie widziemy głowy. 
I w drugiej wersji:

Drzewo w miastach wolności wicher srogi wali.

Mnieman, że wolność sama wprędce się obali.

Reasumując: przywołane utwory ujawniają jednoznaczne stanowisko poety wobec ideologii rewolucji francuskiej. Miały uświadomić rodakom, jak wielkie niebezpieczeństwo niósł ze sobą rewolucyjny terror oraz przestrzec przed grożącymi konsekwencjami.

\section{Bibliografia}

Baczko Bronisław, Hiob, mój przyjaciel. Obietnice szczęścia i nieuchronnośc zła, Warszawa 2002

Bailly Jean-Sylvain, Ocumres posthumes... précédé de la vie littéraire et politique de cet homme illustre, Paris 1810

Baszkiewicz Jan, Meller Stefan, Reu'olucja Francuska 1789-1794. Spoteczeństu'o obyu'atelskie, Warszawa 1983

Estereicher Karol, Bibliografia polska, Kraków 1906

Gaxotte Pierre, Reurolucja francuska, tł. J. Furuhiehm, popr. i uzup. A. Zawilski, E. Kuczkowska, Gdańsk 2001

Grzebień Ludwik, Eabęcki Adam, [hasło w:] Polski stou'nik biograficzny', t. 18, Wrocław 1993

Bibliografia literatury polskiej „Nou'y Korbut”, t. 4-6: Ośu'iecenie, oprac. Elżbieta Alcksandrowska z zespolem, Warszawa 1966-1972

Lenôtre G., Citoyen-Pontife, w: idem, La petite histoire. Sous le bonnet rouge, Paris 1936

Loomis Stanley, Paris in the Terror: June 1793 - July' 1794, London 1964

Salmonowicz Stanisław, Syluretki spod giloty'n', Warszawa 1989 